\title{
PROCESS CAPABILITY STUDY OF A RAPID CASTING SOLUTION FOR ALUMINIUM ALLOYS USING THREE-DIMENSIONAL PRINTING
}

\author{
R. Singh \\ Faculty of Production Engineering \\ Guru Nanak Dev Engg. College \\ Ludhiana-141006, India \\ Phone: +91 98722 57575, Fax: +91 1612502700 , \\ E-mail: rupindersingh78@yahoo.com
}

\begin{abstract}
In the present work, the best shell wall thickness of a mould cavity was investigated in a process capability study of a rapid casting solution for aluminium alloys using threedimensional printing (3DP). Starting from the identification of a component/benchmark, an aluminium-alloy casting prototype was produced with different shell wall thicknesses by three dimensional printing. The results of the study suggest that, at the best shell wall thickness $(5 \mathrm{~mm})$ for aluminium alloys, the rapid casting solution using a 3DP process lies within the \pm 3.999 sigma $(\sigma)$ limit.
\end{abstract}

Keywords: Three-dimensional printing; process capability; aluminium alloys; dimensional accuracy; rapid casting.

\section{INTRODUCTION}

The process of three dimensional printing (3DP) was patented by Sachs et al. (1994) under U.S. patent number 005340656. It was developed at the Massachusetts Institute of Technology (MIT) and licensed to Soligen Corporation, Extrude Hone and Z Corporation of Burlington (Singh and Verma, 2008). Hybrid 3DP is relatively costeffective form of rapid prototyping (RP) (Singh, 2010a). The techniques based on layerby-layer manufacturing have extended their fields of application, from building aesthetic and functional prototypes to the production of tools and moulds for technological prototypes (Karapatis et al., 1998; Singh, 2010b). Technological prototypes can constitute a strategic means, not only for functional and assembly tests or to obtain the customer's acceptance, but also to outline eventual critical points in the production process (Singh and Singh, 2008). The relevance of RP techniques is associated with, above all, a short time for parts availability (Bassoli et al., 2006; Singh and Singh, 2009a). Traditionally, in order to produce cast prototypes, a model and eventual cores had to be created, involving time and costs that did not match the rules of the competitive market (Singh, 2008a). For this reason, functional tests are typically performed on prototypes obtained by metal cutting, which are not effective in outlining issues related to the manufacturing process (Singh, 2010c). The possibility of verifying the usefulness of a technological solution in the early stages of product development ensures a "concurrent engineering" approach and minimises the risk of late modifications to definitive production tools (Bernard et al., 2003). The initial cost increase can thus be repaid through a reduction in costs and time required in the subsequent phases of development, engineering and production, as well as through nonmonetary advantages (Wang et al., 1999). In particular, for relatively small and complex 
parts, the benefits of additive construction can be significant (Dimitrov et al., 2006). In this field, innovative solutions are now available based on 3DP processes, which can extend RP possibilities thanks to lower costs with respect to previous technologies (Singh, 2010d). One such technological solution in shell casting starts from starch patterns produced on 3DP conceptual modellers (Radstok, 1999). A second solution is 3DP technology with the use of a ceramic material which allows for the production of complex cavities and cores, suitable for casting light alloys (Dimitrov et al., 2007). A key issue regarding the shell casting process is the production of the pattern in the case of prototype casting, for which traditional die casting is uneconomical. Rapid prototyping techniques can meet this requirement, producing single/few parts in a short time and without tooling costs (Verma, 2008; Singh and Singh, 2009b,c). The present research investigates shell patterns obtained by 3DP on which the ceramic shell can be built and then joined (as in the conventional process) to obtain a cavity for pouring a metal. Experimental studies regarding this solution are lacking in the literature; in particular, the technological feasibility in the case of thin-walled parts needs to be assessed (Singh, 2008b). In earlier studies, an effort was made through experiments to study the feasibility of decreasing the shell wall thickness from the recommended one $(12 \mathrm{~mm})$, in order to reduce the time of production as well as to evaluate the dimensional accuracy and mechanical properties of the low melting point alloy castings obtained for assembly purposes (Singh, 2010b) Hitherto, less work has been reported on the process capability of the $3 \mathrm{DP}$ process for rapid casting of aluminium alloys. In the current work, 3DP technology was used for rapid shell casting to make shell moulds for aluminium alloys, and a study was conducted to understand the process capability of 3DP. The following objectives were set for the present experimental study:

a) To study the process capability of a rapid casting solution for an aluminium alloy using hybrid 3DP.

b) To evaluate the dimensional accuracy of the castings obtained as per allowed IS standards for the casting process.

\section{EXPERIMENTATION}

In order to accomplish the above objectives, "aluminium alloy casting" was chosen as a benchmark. The component selected for the present study is shown in Figure 1 (Singh and Singh, 2008). The experimental procedure started with drafting/model creation using AutoCAD software (Figure 2).

After the selection of the benchmark, the component to be built was modelled using CAD. The CAD software used for the modelling was UNIGRAPHICS Ver. NX 5. The upper and lower shells of the split pattern were made for different values of the thickness. The thickness values for the shells were 12, 11, 10, 9, 8, 7, 6, 5, 4, 3, 2 and 1 $\mathrm{mm}$. The CAD models of the upper and lower shells were converted in to STL (standard triangulation language) format also known as stereo lithography format. Moulds were manufactured in 3DP (Z Print machine, Model Z 510) with Z Cast 501 powder, and the parts were heat-treated at a temperature of $110^{\circ} \mathrm{C}$ for 1 hour. The upper and lower shells were placed in such a way that the central axis of both shells was collinear. The colinearity of the shells was checked with the help of a surface profilometer, and molten metal was poured for obtaining the aluminium alloy casting prototype (Figure 3). 

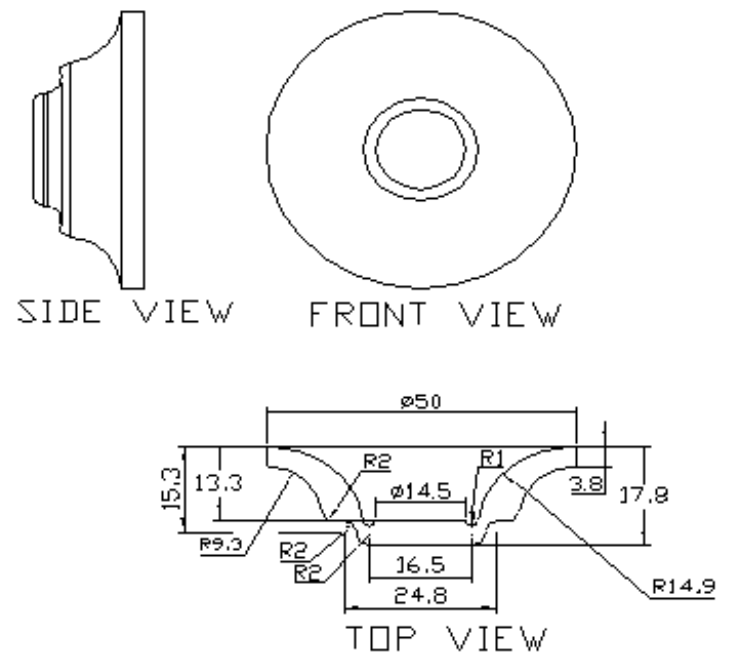

Figure 1. Benchmark dimensions (Singh and Singh, 2008)

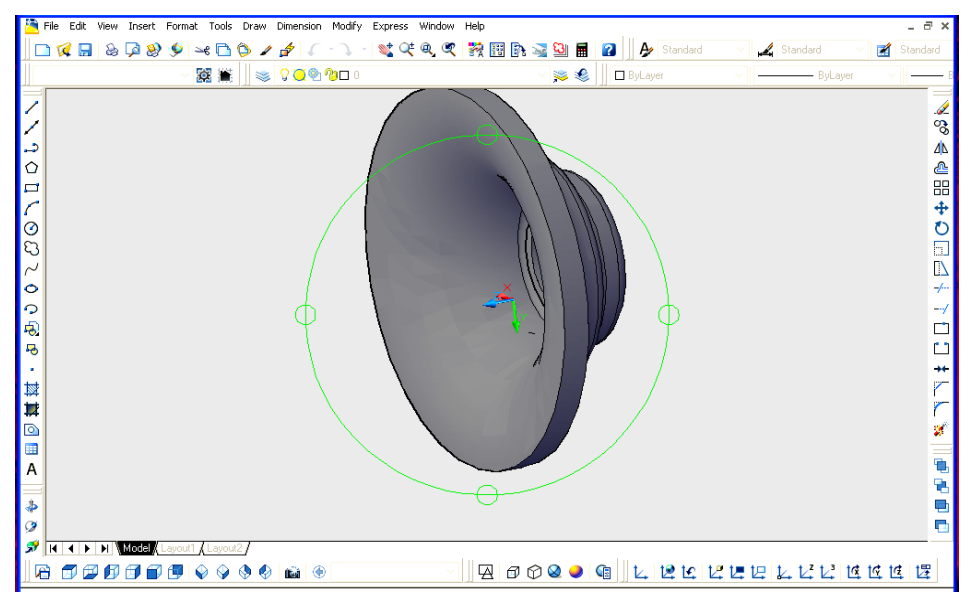

Figure 2. CAD model of the casing chosen as a benchmark (Singh and Singh, 2008)

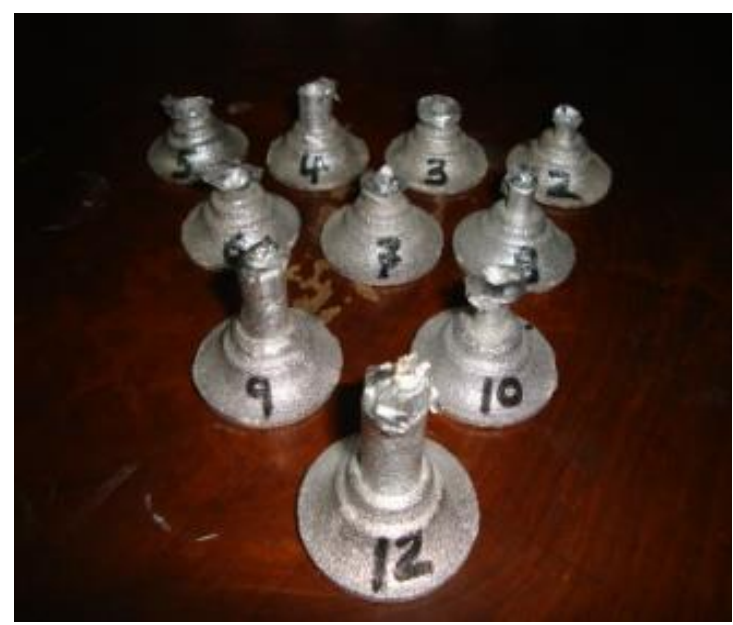

Figure 3. Aluminium alloy casting at different shell wall thicknesses 


\section{RESULTS AND DISCUSSION}

The measurement paths for the internal and the external surfaces of the benchmark were generated through the measurement software of GEOPAK v2.4.R10 CMM. These paths direct the movements of the CMM probe along trajectories normal to the part surface. About 70 points were measured on the external surface. For each point, the machine software evaluated the deviations between the measured positions and the theoretical ones for the $\mathrm{X}, \mathrm{Y}$ and $\mathrm{Z}$ coordinates. Table 1 shows the variation in the measured dimensions of the outer diameter and hardness of castings prepared with respect to shell thickness (mm).

Table 1. Observations of the final experimentation for aluminium alloy casting

\begin{tabular}{cclc}
\hline S. No & $\begin{array}{c}\text { Shell mould thickness } \\
(\mathbf{m m})\end{array}$ & $\begin{array}{c}\text { Avg. diameter } \\
(\mathbf{m m})\end{array}$ & $\begin{array}{c}\text { Hardness } \\
(\mathbf{V H N})\end{array}$ \\
\hline 1 & 12 & 49.151 & 94 \\
2 & 11 & 49.148 & 92 \\
3 & 10 & 49.152 & 93 \\
4 & 9 & 49.022 & 89 \\
5 & 8 & 49.153 & 91 \\
6 & 7 & 49.154 & 94 \\
7 & 6 & 49.169 & 93 \\
8 & 5 & 49.189 & 98 \\
9 & 4 & 49.112 & 94 \\
10 & 3 & 49.016 & 93 \\
11 & 2 & 48.986 & 92 \\
12 & 1 & Broken under metal pressure \\
\hline
\end{tabular}

It should be noted that, in casting, neither higher nor lower hardness is desirable (Kaplas and Singh, 2008); if the casting is of high hardness, it is usually brittle, and with lower hardness, it will be ductile. In the present experimental study, the variation in hardness value was small. The only reason to measure and compare the hardness value was show that, for the optimum size shell thickness prepared by $3 \mathrm{DP}$, the castings produced had little variation in hardness, so there should not be any problem with functional operations. The results of the dimensional measurements were used to evaluate the tolerance unit (n) that derives starting from the standard tolerance factor $\mathrm{i}$, defined in standard UNI EN 20286-1 (1995). The values of standard tolerances corresponding to IT5-IT18 grades, for nominal sizes up to $500 \mathrm{~mm}$, were evaluated considering the standard tolerance factor $\mathrm{i}(\mu \mathrm{m})$ indicated by the following formula, where $\mathrm{D}$ is the geometric mean of the range of nominal sizes in mm (Kaplas and Singh, 2008).

$$
i=0.45 \times D^{1 / 3}+0.001 \times D
$$

In fact, the standard tolerances were not evaluated separately for each nominal size, but for a range of nominal sizes. For a generic nominal dimension $\mathrm{D}_{\mathrm{JN}}$, the number of the tolerance unit's $\mathrm{n}$ is evaluated as follows:

where $\mathrm{D}_{\mathrm{JM}}$ is a measured dimension.

$$
n=1000 \times\left(D_{J N}-D_{J M}\right) / i
$$


Tolerance is expressed as a multiple of I; for example, IT14 corresponds to 400i with $n=400$. Table 2 shows a classification of different IT grades according to UNI EN 20286-1. After this, for each value of the outer diameter, the corresponding value of $n$ was calculated and the latter was taken as a reference index for the evaluation of tolerance grade.

Table 2. IT grades as per UNI EN 20286-1(1995)

\begin{tabular}{|c|c|c|c|c|c|}
\hline \multirow[t]{2}{*}{ S. No } & \multirow{2}{*}{$\begin{array}{c}\text { Shell Mould } \\
\text { Thickness } \\
\text { (mm) }\end{array}$} & \multicolumn{2}{|c|}{$\begin{array}{c}\text { Dimension } \\
(\mathrm{mm})\end{array}$} & \multirow{3}{*}{$\begin{array}{l}\infty \\
\mathfrak{n}\end{array}$} & \multirow[t]{2}{*}{$\begin{array}{c}\text { IT } \\
\text { grade }\end{array}$} \\
\hline & & $\mathbf{D}_{\mathbf{J N}}$ & $\mathbf{D}_{\mathrm{JM}}$ & & \\
\hline 1 & 12 & 50.00 & 49.151 & & IT 14 \\
\hline 2 & 11 & 50.00 & 49.148 & II & IT 14 \\
\hline 3 & 10 & 50.00 & 49.152 & $\approx$ & IT 14 \\
\hline 4 & 9 & 50.00 & 49.022 & ? & IT 14 \\
\hline 5 & 8 & 50.00 & 49.153 & $\underset{\pi}{2}$ & IT14 \\
\hline 6 & 7 & 50.00 & 49.154 & $\ddot{\mathscr{E}}$ & IT 14 \\
\hline 7 & 6 & 50.00 & 49.169 & तై & IT 14 \\
\hline 8 & 5 & 50.00 & 49.189 & 0 & IT 14 \\
\hline 9 & 4 & 50.00 & 49.112 & E & IT 14 \\
\hline 10 & 3 & 50.00 & 49.016 & & IT 14 \\
\hline 11 & 2 & 50.00 & 48.986 & & IT 15 \\
\hline 12 & 1 & Broke & due to $r$ & tal & ressure \\
\hline
\end{tabular}

It should be noted that with a reduction in shell wall thickness, there were no safety problems because the reduction in shell wall thickness was compensated for by supporting loose sand. Furthermore (based upon the observations presented in Table 1), to understand whether the process was statistically controlled, eight samples of aluminium alloy pieces were casted at the best shell thickness value of $5 \mathrm{~mm}$ (which showed the best dimensional accuracy). Upon measurement of the outer diameter with CMM, the dimensions were obtained and are shown in Table 3. Based on the observations in Table 3, the $\mathrm{R}$ chart and the $\mathrm{X}$ chart of the measured values of the outer diameter were developed (Figure 4 and 5). Figure 6 shows the $\mathrm{Cp}$ and $\mathrm{Cpk}$ values for the benchmark prepared with a shell wall thickness of $5 \mathrm{~mm}$.

Table 3. Benchmark dimensional values at a shell wall thickness of $5 \mathrm{~mm}$

\begin{tabular}{cc}
\hline S.NO & OBSERVATIONS \\
\hline 1 & 49.1886 \\
2 & 49.1884 \\
3 & 49.1869 \\
4 & 49.1811 \\
5 & 49.1825 \\
6 & 49.1861 \\
7 & 49.1895 \\
8 & 49.1902 \\
\hline
\end{tabular}




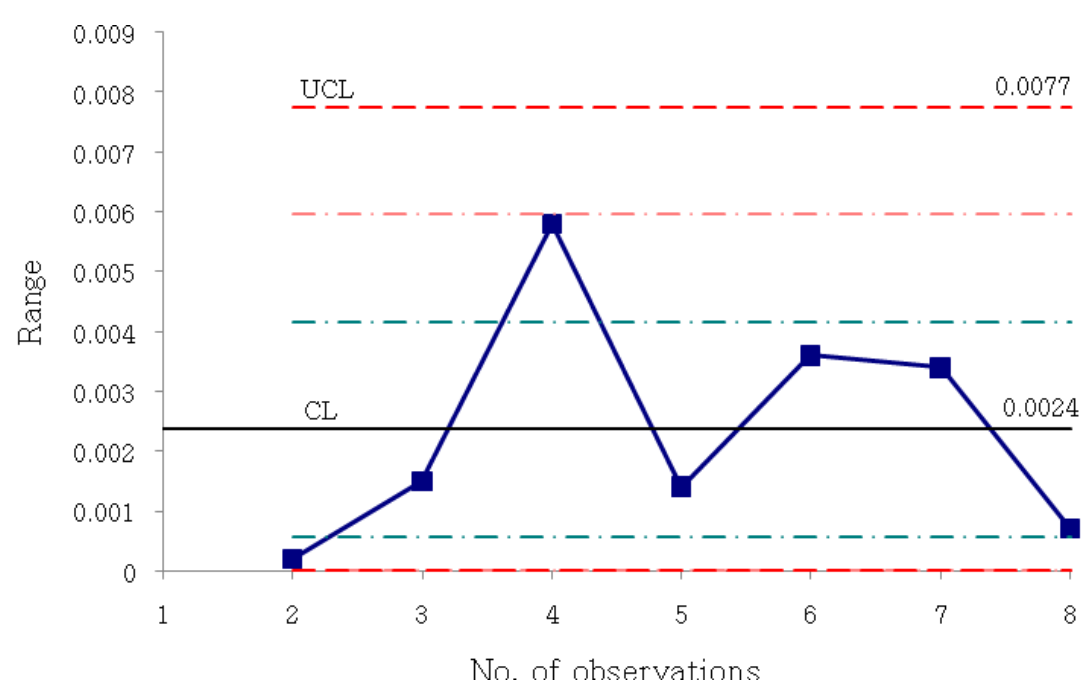

Figure 4. R Chart of aluminium

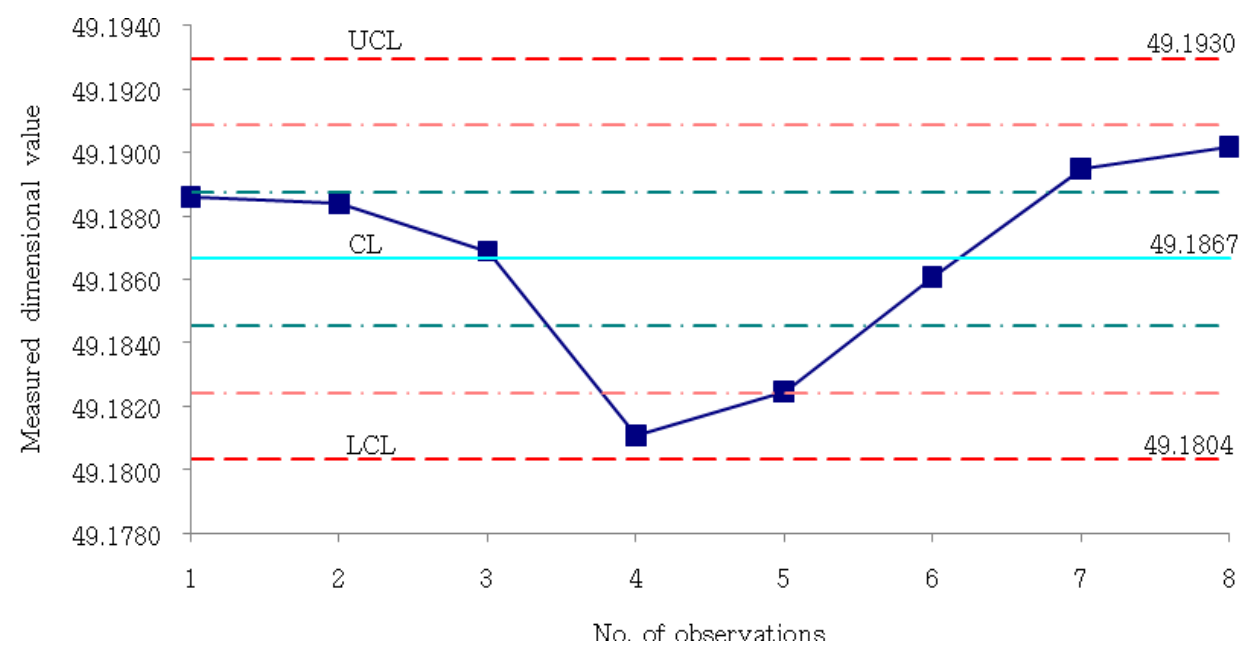

Figure 5. X chart of aluminium

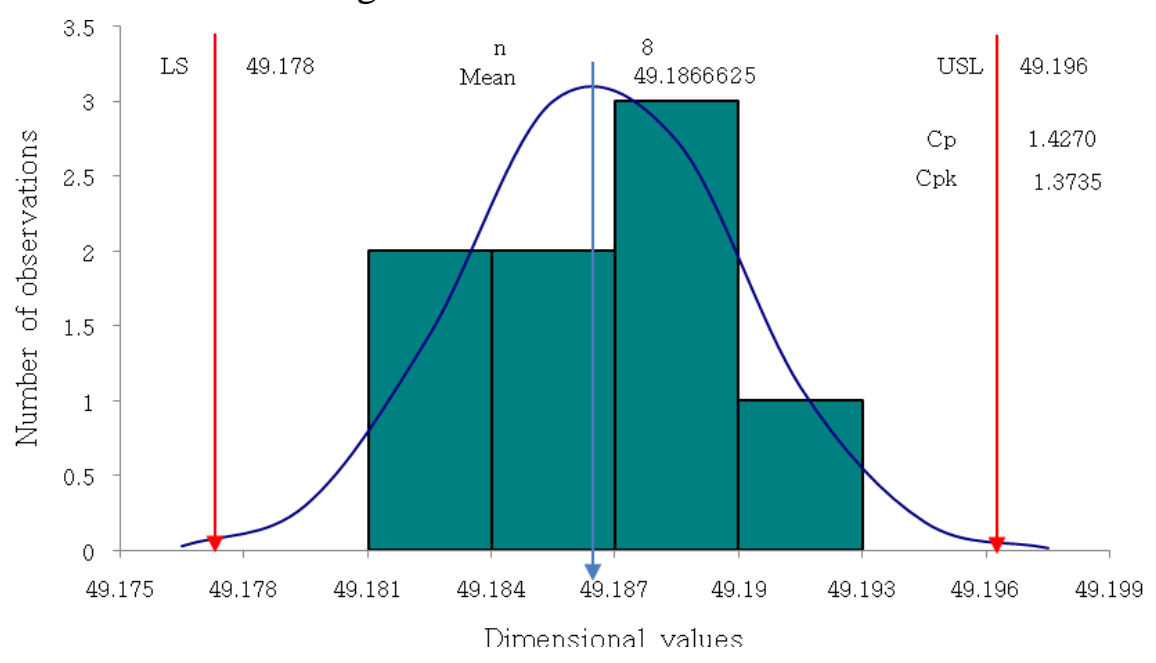

Figure 6. $\mathrm{Cp}$ and $\mathrm{Cpk}$ values for the dimensional values 
For the nominal dimension $\left(\mathrm{D}_{\mathrm{JN}}=50 \mathrm{~mm}\right.$ ), corresponding to a $\mathrm{Cpk}$ value of 1.37, the area under the normal curve was 0.999936360 and the non-conforming parts per million ( $\mathrm{ppm}$ ) were 63.6403. It should be noted that a Cpk value of 1.33 or greater is considered to be an industry benchmark. This means that the process is contained within four standard deviations of the process specifications (Devor et al., 2005). This process will produce conforming products as long as it remains in statistical control. Based on the Cpk value, the $\sigma$ value was calculated using QI Macros 2010 software. The process capability at the best shell wall thickness $(5 \mathrm{~mm})$ for the aluminium alloy lies in the range of $\pm 3.999 \sigma$, using a rapid casting solution and a 3DP process.

\section{CONCLUSIONS}

On the basis of the experimental observations made on the aluminium alloy castings, the following conclusions can be drawn:

1. It is feasible to reduce the shell wall thickness from the recommended value of $12 \mathrm{~mm}$ to $2 \mathrm{~mm}$. The tolerance grades of the castings produced with different thicknesses were consistent with the permissible range of tolerance grades (IT grades) as per standard UNI EN 20286-I (1995). The results are consistent with the observations in other studies. Furthermore, instead of a $12 \mathrm{~mm}$ shell wall thickness of the mould in an aluminium-alloy casting prototype, one can select a $5 \mathrm{~mm}$ shell thickness, as observed from the improved dimensional results and mechanical properties.

2. The Cpk value $>1.33$ with a $5 \mathrm{~mm}$ shell wall thickness demonstrates that a rapid casting solution for aluminium alloys using 3DP is a highly capable process and the process capability lies in the range of $\pm 3.999 \sigma$ limits.

\section{ACKNOWLEDGEMENTS}

The author is thankful to AICTE, New Delhi for financial support under CAYT and the grants-in-aid sanctioned vide letter no. 1-51/FD/CA/17/2007-08.

\section{REFERENCES}

Bassoli, E., Gatto, A., Iuliano, L. and Violante, M.G. 2006. 3D printing technique applied to rapid casting. Rapid Prototyping Journal, 13(3): 148-155.

Bernard, A., Charles, J.D., Perry, N. and Gabriel, S. 2003. Integration of CAD and rapid manufacturing for sand casting optimization. Rapid Prototyping Journal, 9(5): 327-333.

Devor, R.E., Chang, T. and Sutherland, J.W. 2005. Statistical quality design and control contemporary concepts and methods. Second edition. New Jersey: Pearson Prentice Hall.

Dimitrov, D., Schreve, K. and de Beer, N. 2006. Advances in three dimensional printing - State of the art and future perspectives. Rapid Prototyping Journal, 12(3): 136147.

Dimitrov, D., Wijck, W. van, de Beer, N. and Dietrich, J. 2007. Development, evaluation and selection of rapid tooling process chains for sand casting of functional prototypes. Journal of Engineering Manufacture, 221(B9): 14411450. 
Kaplas, M. and Singh, R. 2008. Experimental investigations for reducing wall thickness in zinc shell casting using three dimensional printing. Journal of Mechanical Engineering Sciences (Proceedings of IMechE Part C), 222(C12): 2427-2431.

Karapatis, N.P., Griethuysen, J.P.S. and Glardon, R. 1998. Direct rapid tooling: a review of current research. Prototyping Journal, 4(2): 77-89.

Radstok, E.1999. Rapid tooling. Rapid Prototyping Journal, 5(4): 164-168.

Sachs, E.M., Haggerty, J.S., Cima, M.J. and Wiliams, A.P. 1994. Three dimensional printing techniques. United States Patent No. US 005340656.

Singh, J.P. and Singh, R. 2009a. Comparison of rapid casting solutions for lead and alloys using three dimensional printing. Journal of Mechanical Engineering Sciences (Proceedings of IMechE Part C), 223(C9): 2117-2123.

Singh, J.P. and Singh, R. 2009b. Investigations for statistically controlled rapid casting solution of lead alloys using three dimensional printing. Journal of Mechanical Engineering Sciences (Proceedings of IMechE Part C), 223(C9): 2125-2134.

Singh, J.P. and Singh, R. 2009c. Investigations for statistically controlled rapid casting solution of low brass alloys using three dimensional printing. International Journal of Rapid Manufacturing, 1(2): 208-221.

Singh, J.P. and Singh, R. 2008. Investigations for reducing wall thickness in low brass rapid casting using three dimensional printing. Proceedings of the International Conference on Advances in Mechanical Engineering (AME 2008), pp. 878-883.

Singh, R. 2008a. Comparison of wall thickness in shell casting of light alloys for generating cost effective prototype using 3DP. $2^{\text {nd }}$ International and $23^{\text {rd }}$ All India Manufacturing Technology, Design and Research Conference, pp. 10891093.

Singh, R. 2008b. Three dimensional printing for casting applications: A state of art review and future perspectives. Proc. of International conference on Advances in Materials and Processing Technologies, pp. 311.

Singh, R. 2010a. Three dimensional printing for casting applications: A state of art review and future perspectives. Advanced Materials Research, 83-86: 342-349.

Singh, R. 2010b. Comparison of statistically controlled machining solutions of Titanium alloys using USM. International Journal of Automotive and Mechanical Engineering, 1: 66-78.

Singh, R. 2010c. Effect of moulding sand on statistically controlled hybrid rapid casting solution for zinc alloys. Journal of Mechanical Science and Technology, 24(8): 1689-1695.

Singh, R. 2010d. An overview of three dimensional printing for casting applications. International Journal of Precision Technology, 2(1): 93-116.

Singh, R. and Verma, M. 2008. Investigations for reducing wall thickness of aluminium shell casting using three dimensional printing. Journal of Achievements in Materials and Manufacturing Engineering, 31(2): 565-569.

UNI EN 20286-1, 1995. ISO system of limits and fits. Bases of tolerances, deviations and fits.

Verma, M. 2008. Investigations for reducing wall thickness in aluminum shell casting using 3DP. M. Tech. Thesis, P.T.U. Jalandhar, India.

Wang, W., Conley, J.G. and Stoll, H.W. 1999. Rapid tooling for sand casting using laminated object manufacturing process. Rapid Prototyping Journal, 5(3): 134140. 